\title{
Suppression of the Hemolytic Effect of Mesoporous Silica Nanoparticles after Protein Corona Interaction: Independence of the Surface Microchemical Environment
}

\author{
Amauri J. Paula, ${ }^{*, \#, a}$ Diego Stéfani T. Martinez, ${ }^{*, a}$ Roberto T. Araujo Júnior, ${ }^{b}$ \\ Antonio G. Souza Filho ${ }^{c}$ and Oswaldo L. Alves*,\#,a \\ ${ }^{a}$ Laboratório de Química do Estado Sólido, Instituto de Química, Universidade Estadual de Campinas, \\ CP 6154, 13083-970 Campinas-SP, Brazil \\ ${ }^{b}$ Departamento de Bioquímica, Universidade Federal de São Paulo, 04044-020 São Paulo-SP, Brazil

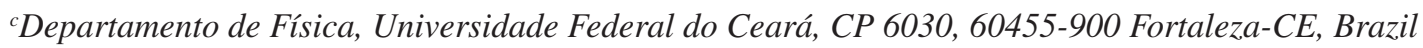

\begin{abstract}
Nanopartículas mesoporosas de sílica são conhecidas por induzirem hemólise de células vermelhas do sangue (RBCs) humano quando ensaios de citotoxicidade são feitos em soluçãotampão de fosfato (PBS). Entretanto, em uma abordagem mais realista, a presença de biomoléculas do plasma sanguíneo precisa ser considerada em qualquer avaliação nanotoxicológica de nanopartículas porosas de $\mathrm{SiO}_{2}$ quando se objetiva a sua utilização em aplicações biomédicas através de administração intravenosa. Nesse contexto, demonstrou-se neste trabalho que nanopartículas porosas de sílica não induzem nenhum efeito citotóxico em células vermelhas do sangue quando ensaios de hemólise são feitos na presença de plasma sanguíneo, independentemente da carga superficial (positiva ou negativa) da nanopartícula. A ausência de hemólise está principalmente associada à adsorção de proteínas do plasma sobre a superfície das nanopartículas, levando à formação de um recobrimento proteico estável (denominado protein corona ou PC) que blinda o ambiente microquímico original das nanopartículas.
\end{abstract}

Mesoporous silica nanoparticles are known to induce the hemolysis of human red blood cells (RBCs) when citotoxicity assays are performed in a phosphate buffer solution (PBS). However, in a more realistic approach, the presence of blood plasma biomolecules must be considered in any nanotoxicological evaluation of porous $\mathrm{SiO}_{2}$ nanoparticles when biomedical applications through intravenous administration are aimed. In this context, it is demonstrated in this work that porous silica nanoparticles do not induce any cytotoxic effect on RBCs when hemolysis assay is done in the presence of blood plasma, regardless the surface charge (positive or negative) of the nanoparticle. The absence of hemolysis is mainly associated with the adsorption of plasma proteins on the nanoparticle surface, which leads to the formation of a stable protein coating (called protein corona or PC) that shields the original microchemical environment of bare nanoparticles.

Keywords: nanoparticles, $\mathrm{SiO}_{2}$, mesopores, hemolytic effect, protein corona

\section{Introduction}

Since porous silica nanoparticles were elected as possible protagonists in a future revolution of several medical processes of theranosis, they have been widely studied during the last decade through the host-guest approach, thus resulting in promising perspectives mainly in the areas of detection ${ }^{1-3}$ and treatment of tumors. ${ }^{4-7}$ While part of the scientific community creatively advances

*e-mail: amaurijp@gmail.com,diegostefani.br@gmail.com, oalves@iqm.unicamp.br

\#These authors contributed equally to the elaboration of this work. towards the engineering of porous silica nanostructures, others are acting in a proactive approach by considering environmental and toxicological effects of nano-based silica materials. In the latter context, several in vitro citotoxicity assays indicated a very high biocompatibility of porous silica nanoparticles. ${ }^{8-10}$ However, a desirable in vivo biocompatibility is not straightforward. For instance, it is well known that amorphous silica particles induce toxicity on human red blood cells (RBCs) and, consequently, this test is being used as a key indicator towards the safe production of $\mathrm{SiO}_{2}$ platforms for nanomedicine through intravenous administration. Although the mechanism of the silica-induced hemolysis phenomenon is not yet totally 
understood, it is known that the hemolytic effect is mainly associated with the surface microchemical environment of silica, which consists primarily of silanol groups $(\mathrm{Si}-\mathrm{OH})$ that can ionize and interact with phosphatidylcholine groups of RBC membranes leading to their disruption. ${ }^{11,12}$ Consequently, the density of silanol groups over the surface was proved to be directly related with the hemolysis, although this relationship is not strictly predictable.

Since the engineering of silica nanostructures advanced along the last decade, parameters other than the concentration of silanol groups at the nanoparticle surface were recognized as being responsible for the toxicity on RBCs. In this way, the evaluation of the dependence of the size and shape of porous $\mathrm{SiO}_{2}$ nanostructures on the hemolysis of RBCs has been systematically done during the last years. Firstly, it was observed that silanol groups on mesoporous silica structures induce less hemolytic effect compared to rigid spherical nanoparticles possibly due to shape-induced effects, which determine the spatial availability of silanols on the nanoparticle-cell interface. ${ }^{13}$ Further, it was observed that: (i) smaller Stöber silica nanoparticles $(24 \mathrm{~nm})$ induce a pronounced hemolytic effect when compared with bigger ones $(263 \mathrm{~nm}),{ }^{14}$ (ii) nanostructures with high aspect ratio (nanorods) are more cytotoxic than spherical nanoparticles ${ }^{15}$ (iii) mesoporous silica nanostructures (MSNs) with ordered pores (MCM-41) induce a stronger hemolytic effect compared with non-ordered; ${ }^{14}$ (iv) small mesoporous nanoparticles $(20 \mathrm{~nm}$ ) consisted of ethenylenebridged silsesquioxane present very low toxicity ${ }^{16}$ and $(v)$ polymers such as PEG (polyethylene glycol) can be used to coat particles in order to greatly reduce the hemolysis. ${ }^{17}$ Furthermore, an extensive assessment of the interaction of bare and functionalized porous silica nanomaterials with RBCs concluded that SBA-15-type MSNs cause the deformation of RBCs and consequently lead to their disruption. Amine functionalizations on the surfaces of MSNs also reduce the hemolytic effect. ${ }^{18}$ However, despite all improvements achieved so far on the $\mathrm{SiO}_{2}$ surface chemistry aiming to overcome the citotoxicity issues, a key parameter must be now considered when dealing with interactions of nanostructures in biological media. Dawson's group at UCD, Dublin, has demonstrated that the adsorption of plasma biomolecules on the nanoparticle surface leads to the formation of a stable biomolecule coating, which has been called protein corona (PC)..$^{19,20}$ The composition of this coating changes over time because the adsorption is a dynamical process in which there is exchange between the constituents of the corona and biological medium. PC has been divided into two main components named "hard" and "soft" coronas, which are characterized by "long" and "short" exchange times, respectively. These coatings greatly influence on the way that the nanometer entity is "seen" by cell and organs. ${ }^{21,22}$ In this case, the dependence of size, porous structure and surface chemistry of $\mathrm{SiO}_{2}$ nanoparticles on the hemolysis of RBCs may manifest differently when such nanostructures interact with proteins of the human blood plasma and, consequently, the final effect on RBCs is a result of the PC formation and not only of the bare silica surface itself. In this context, it is important to call the attention for the suppression of the hemolysis when the assay is performed in the blood plasma medium.

In this paper, it is demonstrated that porous $\mathrm{SiO}_{2}$ nanoparticles in the sub-hundred nanometer range with three different surface microchemical environments (and electrochemical features) do not induce toxicity on RBCs when evaluated in the presence of human blood plasma, thereby contrasting with the pronounced hemolytic effect observed when the assay is done in phosphate buffer solution (PBS).

\section{Experimental}

\section{Synthesis of porous silica nanoparticles}

In order to evaluate these surface effects above mentioned, silica nanoparticles with a size distribution from 40-80 $\mathrm{nm}$ and pore size around $2 \mathrm{~nm}$ were produced through a sol-gel method previously reported ${ }^{23}$ This methodology is basically a modification of the Stöber method, ${ }^{24}$ which uses TEOS (tetraethyl orthosilicate) as the Si precursor and ammonia solution $\left(\mathrm{NH}_{3}\right)$ as the basic catalyst. The synthesis of porous silica nanoparticles was carried out under a high concentration of precursors, which grants highly uniform spherical-shaped nanoparticles. For this, $0.75 \mathrm{~g}$ of cetyltrimethylammonium bromide (CTAB) was dissolved in $20.0 \mathrm{~mL}$ of a $\mathrm{NH}_{3}$ aqueous solution $\left(0.048 \mathrm{~mol} \mathrm{~L}^{-1}\right)$ and the final solution was homogenized under magnetic stirring in a round-bottomed distillation flask attached to a reflux condenser at $5{ }^{\circ} \mathrm{C}$ (to avoid ethanol evaporation). To this solution, $3.20 \mathrm{~mL}$ of absolute ethanol were added as the cosolvent and the mixture was homogenized for $15 \mathrm{~min}$ at $60{ }^{\circ} \mathrm{C}$. Sequentially, $2.50 \mathrm{~mL}$ of TEOS $(1.20 \mathrm{mmol})$ were inserted and the flask was kept at the same temperature for $2 \mathrm{~h}$ under stirring. By ending the reaction, products were isolated by centrifugation at 17,949 $\mathrm{rcf}$ (Beckman Coulter, Brea, USA) and washed with absolute ethanol before the extraction of the soft-template (CTAB). Finally, the sample was washed twice with absolute ethanol and dried at $60{ }^{\circ} \mathrm{C}$ for $24 \mathrm{~h}$. This sample was named $\mathrm{Si}-\mathrm{OH}$, according to the surface microchemical environment, which consists of silanol groups. Details regarding the extraction process 
of CTAB are described in the Supplementary Information (SI) section.

\section{Surface functionalization of porous silica nanoparticles}

The influence of the surface microchemical environment on the hemolysis of RBCs was evaluated through the strict decoration of the nanoparticle surface in order to generate antagonistic electrochemical environments (negatively and positively charged) as a function of the organosilanes used for functionalization. These different microchemical environments would provide useful insights regarding possible chemical interactions occurring with RBCs. For the first case, the negatively charged surface, a hierarchical functionalization of the nanoparticle with propylmethylphosphonate (an ionizable group) was achieved by a sequential addition of the organosilane as a function of the reaction time. This co-condensation method was introduced by Bein and co-workers. ${ }^{25}$ In this way, $127.7 \mu \mathrm{L}$ of 3-(trihydroxysilyl)-propylmethyl-phosphonate (THSPMP) were added after $90 \mathrm{~min}$ of synthesis, time in which most of silica monomers are already condensed as nanoparticles. The quantity of THSPMP used represents an excess of $2.5 \% \mathrm{~mol}$ of silicon based on the quantity used for the production of sample $\mathrm{Si}-\mathrm{OH}$. In this approach, just an external decoration was promoted during the last $30 \mathrm{~min}$ of reaction, while the internal porous structure is preserved as the same as for sample $\mathrm{Si}-\mathrm{OH}$. All synthetic conditions and experimental apparatus were the same used for the synthesis of sample $\mathrm{Si}-\mathrm{OH}$. This sample was named $\mathrm{Si}-\mathrm{P}\left(\mathrm{CH}_{3}\right) \mathrm{O}_{3} \mathrm{H}$.

In order to obtain a positively charged surface on the silica porous nanoparticles, a decoration with 3-aminopropyl moieties was carried out by a different process once the co-condensation of its respective organosilane (3-aminopropyltrietoxysilane or APTES) induces a variation in the $\mathrm{pH}$ that leads to the production of elongated nanoparticles (aggregated). In this way, the modification of the silica surface was done by a post-grafting process of sample $\mathrm{Si}-\mathrm{OH}$. The residual CTAB still present in the pores of the $\mathrm{SiO}_{2}$ nanoparticles hinders the attachment of APTES on the internal porous structure, thus restricting the decoration on the external surface. For this, $290 \mathrm{mg}$ of sample $\mathrm{Si}-\mathrm{OH}$ (before submitting to the extraction process of CTAB) were resuspended by sonication in $40 \mathrm{~mL}$ of ethanol for $30 \mathrm{~min}$ and transferred to a round-bottomed distillation flask attached to a reflux condenser at $5{ }^{\circ} \mathrm{C}$. The suspension was homogenized under stirring for $15 \mathrm{~min}$ at $60{ }^{\circ} \mathrm{C}$, and then $730 \mu \mathrm{L}$ of APTES were added to the mixture (excess of $25 \% \mathrm{~mol}$ of silicon based on sample $\mathrm{Si}-\mathrm{OH})$. The reaction was kept under stirring at $60{ }^{\circ} \mathrm{C}$ for $60 \mathrm{~min}$ and at room temperature for $24 \mathrm{~h}$. The percentage of silicon (\% mol of Si) per gram of sample $\mathrm{Si}-\mathrm{OH}$ was calculated through a thermogravimetric analysis by considering the residue above $850^{\circ} \mathrm{C}$ as being just silicon dioxide $\left(\mathrm{SiO}_{2}\right)$. After the synthesis, products (sample $\mathrm{Si}-\mathrm{NH}_{2}$ ) were isolated by centrifugation at 17,949 rcf and washed with absolute ethanol before the extraction of the soft-template (CTAB). Finally, the sample was washed twice with absolute ethanol and dried at $60^{\circ} \mathrm{C}$ for $24 \mathrm{~h}$. More details regarding the experimental procedures as well as the characterization methods are provided in the SI section.

Incubation of $\mathrm{SiO}_{2}$ nanoparticles with human blood plasma

The preserved human blood plasma $(250 \mathrm{~mL})$ was obtained from the Hemocenter of Campinas at the University of Campinas (Unicamp, São Paulo State, Brazil). For the formation of the protein-coated nanoparticles, the plasma was firstly centrifuged at 17,949 $\mathrm{rcf}$ for $10 \mathrm{~min}$ and the supernatant was used in the experiments. Porous $\mathrm{SiO}_{2}$ nanoparticles $\left(5.0 \mathrm{mg} \mathrm{mL}^{-1}\right.$ in deionized water) were then incubated with the centrifuged plasma at $55 \%$ for $1 \mathrm{~h}$ at room temperature in microcentrifuge tubes (Eppendorf, Hamburg, Germany). After that, the tubes were centrifuged for 17,949 $\mathrm{rcf}$ for $30 \mathrm{~min}$, the supernatant was discarded and the obtained pellets (nanoparticles-PC complexes) were washed for 3 times with a phosphate buffer solution to remove the excess of unbound plasma proteins. In order to demonstrate the protein corona formation, dynamic light scattering (DLS) measurements (Malvern, Malvern, UK) were performed by using $50 \mu \mathrm{gL}^{-1}$ of bare and PC-nanoparticles in deionized water (DI water).

\section{Hemolysis assay}

The impact of the nanoparticle surface chemistry on human red blood cells (RBCs) and the influence of the protein corona interaction on this process were evaluated by the standard hemolysis assays. ${ }^{26}$ It was used RBCs from preserved human blood, obtained from the Hemocenter of Campinas at the University of Campinas (Unicamp). A volume of $8 \mathrm{~mL}$ of blood was added to $0.8 \mathrm{~mL}$ of a $3.8 \%$ sodium citrate solution in a $15 \mathrm{~mL}$ Falcon tube to prevent coagulation. The blood was mixed gently and centrifuged at 10,000 rcf for $10 \mathrm{~min}$. The supernatant was discarded and RBCs were washed 5 times by suspending them in a phosphate buffer saline solution ( $\mathrm{pH}$ 7.4). The final suspension used for the hemolysis assay consisted of 5\% (v/v) of RCBs in a phosphate buffer solution. To evaluate the hemolytic effect, different concentrations of nanoparticles were incubated with RBCs (200 $\mu \mathrm{L}$ of a $5 \%$ suspension) 
in the presence and absence of blood plasma at $2 \%(20$ $\mu \mathrm{L}$ of centrifuged plasma) in a phosphate buffer solution in sterile microcentrifuge tubes. The tubes were incubated for $2 \mathrm{~h}$ at room temperature through a static method after gently homogenization. The final volume of the hemolysis assay in all experiments was $1.0 \mathrm{~mL}$. After the incubation, tubes were centrifuged for $5 \mathrm{~min}$ and $100 \mu \mathrm{L}$ were carefully removed from each tube and transferred to a clean 96-well plate. The quantification of hemoglobin in the supernatant of a nanoparticle-RBC mixture and nanoparticle-protein corona-RBC mixture was done by recording the absorbance of hemoglobin at $540 \mathrm{~nm}$ (Shimadzu, Kyoto, Japan). The positive control consisted of $0.8 \mathrm{~mL}$ of deionized water and $0.2 \mathrm{~mL}$ of a RBCs suspension at $5 \%$. The negative control consisted of $0.8 \mathrm{~mL}$ of a phosphate buffer solution and $0.2 \mathrm{~mL}$ of the RBCs suspension (5\%). The percentage of hemolysis was calculated by using the linear equation $\mathrm{y}=\mathrm{mx}$ $+\mathrm{c}$, where the percentage of hemolysis $(\mathrm{x})=$ [optical density (y) - negative control optical density (c)] / [(positive control optical density - negative control optical density)/100]. To demonstrate the influence of the specific surface area of porous $\mathrm{SiO}_{2}$ nanoparticles on the hemolytic effect, the amount of nanoparticles used in the hemolysis assay was normalized according to the specific surface area estimated through the BET method.

\section{Results and Discussion}

The spherical morphology of the synthesized silica nanoparticles is highly uniform for the three samples produced, presenting diameters which vary from approximately 40 $-80 \mathrm{~nm}$, as observed through bright-field transmission electron microscopy (BF-TEM, see Figure 1) and through the nanoparticle size distribution (insets, Figure 1) resulted from the measurement of the Feret diameter of at least 100 particles observed in the images. An examination of the porosity by nitrogen adsorption-desorption experiments shows the presence of a complex porous structure, manifested in a type II isotherm with a H3-like hysteresis for all samples (IUPAC classification). However, a subtle stepwise behavior is observed around $\mathrm{P} / \mathrm{P}_{0}=0.4$ (see Figure S1a in the SI section), which is related to a capillarity phenomenon, typical of ordered mesopore structures. The specific surface area of the samples varied from $855 \mathrm{~m}^{2} \mathrm{~g}^{-1}$ for the bare silica (sample $\mathrm{Si}-\mathrm{OH}$ ) to the minimum value of $624 \mathrm{~m}^{2} \mathrm{~g}^{-1}$ for sample $\mathrm{Si}-\mathrm{NH}_{2}$, thus indicating that the degree of surface functionalization with aminopropyl and propylmethylphosphonate radicals causes just a minor obstruction of the porous cavities. As further shown, this decrease in the specific surface area is proportional to the amount of condensed groups on the particle surface. Parallely, pore volumes presented a subtle increase with the surface functionalization of the nanoparticles, varying from 0.8 to $1.1 \mathrm{~cm}^{3} \mathrm{~g}^{-1}$ (see Table 1). The size distribution of the non-ordered pores calculated through the BJH method from the $\mathrm{N}_{2}$ adsorption branch spans from less than 2 to $5 \mathrm{~nm}$ (see Figure S1b in the SI section), thus comprising pores that cover the micro- and mesopore size classification. With the use of the high angle annular dark-field transmission electron microscopy (HAADF-TEM), the greater contrast differences based on the electron scattering phenomenon from sample thickness allowed an accurate pore size distribution measurement, indicating an average diameter of $1.8 \mathrm{~nm}$ (standard deviation $=0.5) \cdot{ }^{23}$ Due to the low amount of surface functionalizing organic groups used as well as due to the overlapping of bands in Fourier transform infrared (FTIR) spectra, vibrational fingerprints are not suitable for either identification or quantification of the functionalizing radicals on the nanoparticles. In this way, the confirmation of the external functionalization on the $\mathrm{SiO}_{2}$ nanoparticles was done through ${ }^{13} \mathrm{C}$ nuclear magnetic resonance (NMR) with the method of cross polarization and magic angle spinning of neighboring ${ }^{1} \mathrm{H}$ nuclei (CPMAS). As observed in the chemical structure diagram and NMR spectra (see Figures S2 and S3a in the SI section), the presence of carbon atoms relative to propylamine and propylmethylphosphonate groups is evidenced in the range from 0 to $80 \mathrm{ppm}$ of ${ }^{13} \mathrm{C}$ NMR spectra. As expected, ethoxy $\left(\mathrm{Si}-\mathrm{O}-\mathrm{CH}_{2} \mathrm{CH}_{3}\right)$ groups originated from the extraction process of $\mathrm{CTAB}$ with the ethanolic solution of hydrochloric acid are evidenced, as well as carbon atoms related to residues of CTAB inside the pores. The degree of condensation of the organosilanes was obtained through ${ }^{29} \mathrm{Si} \mathrm{NMR}$ with the method of high-power decoupling (HPDEC, ${ }^{29} \mathrm{Si} \rightarrow{ }^{1} \mathrm{H}$ ), which provides a quantitative relation between the different silicon sites present in the samples. After deconvolution of peaks with Gaussian functions (see Figures S3b, S3c and S3d in the SI section), the calculus indicated that there are approximately 7.1 and $2.0 \%$-mol of silicon bonded to propylamine and propylmethylphosphonate groups, respectively. Surface electrochemical features achieved with the functionalization on each nanoparticle are observed through zeta potential measurements (see Table 1). The results indicated the presence of a more positively-charged surface for sample $\mathrm{Si}-\mathrm{NH}_{2}$ and a more negative surface for sample $\mathrm{Si}-\mathrm{P}\left(\mathrm{CH}_{3}\right) \mathrm{O}_{3} \mathrm{H}$. By considering the deviation of about $200 \mathrm{~m}^{2} \mathrm{~g}^{-1}$ in the specific surface area value, this parameter was normalized for the hemolysis experiments. In this way, differences in the RBC citotoxicity could be associated to the peculiar surface characteristics of the nanoparticles. 
Table 1. Details of the functionalized porous silica nanoparticles

\begin{tabular}{lccccc}
\hline Samples & $\begin{array}{c}\text { Specific surface area } / \\
\left(\mathrm{m}^{2} \mathrm{~g}^{-1}\right)\end{array}$ & $\begin{array}{c}\text { Pore volume } \\
\left(\mathrm{cm}^{3} \mathrm{~g}^{-1}\right)\end{array}$ & & \multicolumn{3}{c}{ Zeta potential $(\xi)^{\mathrm{c}} / \mathrm{mV}$} \\
\cline { 4 - 6 } $\mathrm{Si}-\mathrm{OH}$ & 855 & 0.8 & -4.6 & $\mathrm{pH} \mathrm{7}$ & -10 \\
$\mathrm{Si}-\mathrm{NH}_{2}$ & 624 & 0.9 & 13 & 6.3 & -11 \\
$\mathrm{Si}-\mathrm{P}_{2}\left(\mathrm{CH}_{3}\right) \mathrm{O}_{3} \mathrm{H}$ & 773 & 1.1 & -7.1 & -13 & -2.5 \\
\hline
\end{tabular}

a Results from the $\mathrm{N}_{2}$ adsorption branch using the BET method; bevaluated through the single-point value adsorbed at the relative pressure (P/P $\left.\mathrm{P}_{0}\right)$ of 0.94 ; cmeasured with nanoparticle and buffer concentrations of $0.071 \mathrm{mg} \mathrm{mL}^{-1}$ and $7.1 \%(\mathrm{v} / \mathrm{v})$, respectively.
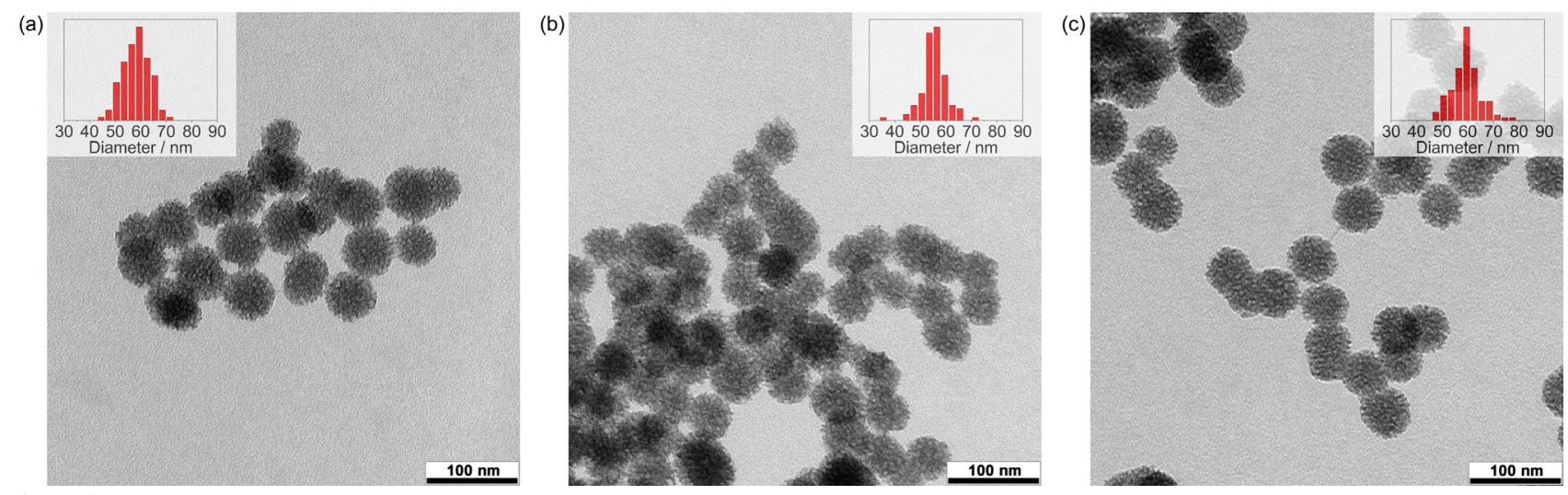

Figure 1. TEM micrographs (bright field mode) of samples (a) Si-OH, (b) $\mathrm{Si}-\mathrm{NH}_{2}$ and (c) $\mathrm{Si}-\mathrm{P}\left(\mathrm{CH}_{3}\right) \mathrm{O}_{3} \mathrm{H}$. Respective histograms are inserted in the corresponding image. The size distributions are results of a counting of at least 100 nanoparticles.

The surface electrochemical characteristics between samples $\mathrm{Si}-\mathrm{OH}, \mathrm{Si}-\mathrm{NH}_{2}$ and $\mathrm{Si}-\mathrm{P}\left(\mathrm{CH}_{3}\right) \mathrm{O}_{3} \mathrm{H}$ reflected in a very little differentiation on the adsorption features of proteins when the nanoparticles were dispersed in human blood plasma (55\% of blood plasma). After several washing and centrifugation runs to ensure the elimination of weakly adsorbed biomolecules (i.e., "soft" corona), the presence of strongly adsorbed proteins (i.e., "hard" corona) $)^{21}$ on the porous silica nanoparticle surface is directly evidenced through dynamic light scattering analyses (DLS), which indicated larger particle diameters for the protein-coated nanoparticles (see Figure 2). The increase in the diameter after the interaction with the blood plasma varied from about 15 to $30 \mathrm{~nm}$. The greater degree of functionalization in sample $\mathrm{Si}-\mathrm{NH}_{2}$ (ca. $7 \% \mathrm{~mol}$ of $\mathrm{Si}$, as seen through ${ }^{29} \mathrm{Si} \mathrm{HPDEC} \mathrm{NMR)} \mathrm{compared} \mathrm{to} \mathrm{Si}-\mathrm{P}\left(\mathrm{CH}_{3}\right)$ $\mathrm{O}_{3} \mathrm{H}$ (ca. $2 \% \mathrm{~mol}$ of $\mathrm{Si}$ ) did not induce a variation in the hydrodynamic radius. The monodispersity of the three samples is confirmed through the polydispersity index (PdI) obtained for the suspensions in deionized water (DI), whose values were observed to be below 0.13 for all samples. After the dispersion in the biological medium (55\% of blood plasma), although the presence of the "hard" corona led to an increase of the nanoparticles sizes, the polydispersity index did not change (below $0.13)$. Zeta potential values for protein-coated silica nanoparticles at a $\mathrm{pH}$ of 7.4 (PBS) were all negative and no significant variations were observed for the three samples (average $=-14.3 \pm 9.2 \mathrm{mV}$ ).

The schematic diagram presented in Figure 3 summarizes the surface groups sitting on the nanoparticles which were used to probe the different interaction possibilities with the constituents from the human blood plasma. This might result in different toxicological effects of the porous silica nanoparticle on RBCs. Initially, by neglecting particular interactions with RBCs that might emerge from stereochemical considerations as well as from hydrogen bonds and van der Waals forces (peculiar for each chemical moiety use), it would be considered here just the interactions arisen from an electrostatic point of view (Coulomb forces), through ionization and protonation events that lead to antagonistically charged chemical radicals. Furthermore, the key event being considered responsible for the hemolysis is the interaction with RBC membranes, while secondary metabolic effects induced by the presence of porous silica nanoparticles are being neglected by the approaches reported so far in the literature. ${ }^{14-16,18}$

As it has been recently reported, ${ }^{21,22,27}$ the dynamic interaction phenomenon occurring in biological media in which biomolecules may adsorb on a nanoparticle surface (and also desorb from it) results in a corona coating (illustrated in Figure 3b) that will play a key role in all further biological effects manifested in a living organism. In a more specific case, the influence of these coatings on 


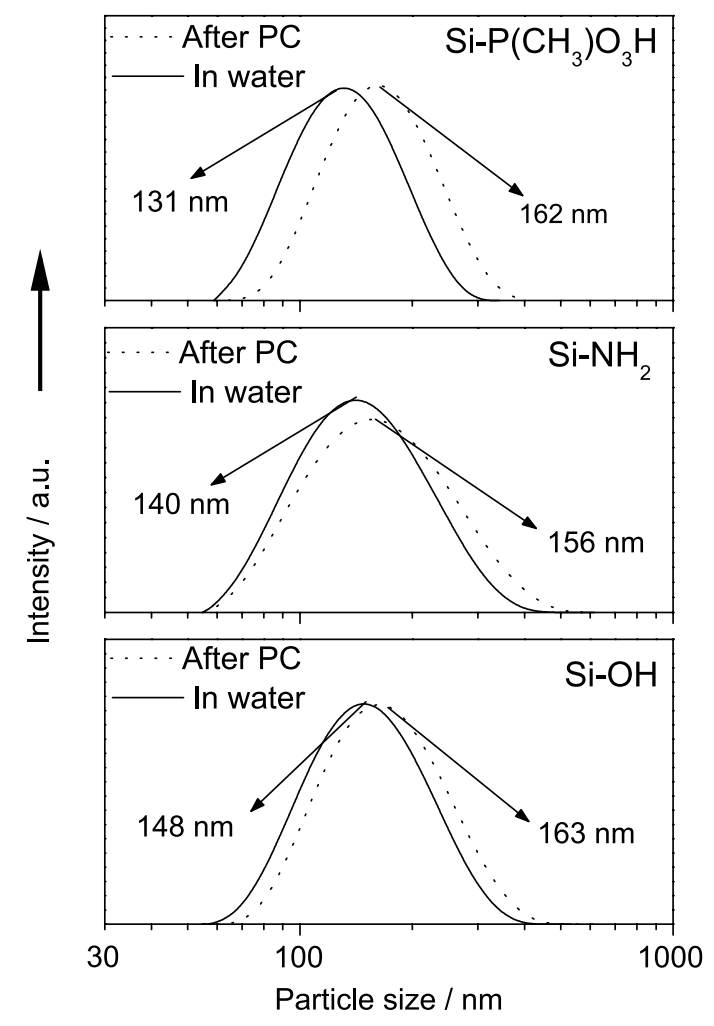

Figure 2. DLS measurements of samples $\mathrm{Si}-\mathrm{OH}, \mathrm{Si}-\mathrm{NH}_{2}$ and $\mathrm{Si}-\mathrm{P}\left(\mathrm{CH}_{3}\right) \mathrm{O}_{3} \mathrm{H}$ in deionized water (full line) and the same samples after the protein corona $(\mathrm{PC})$ interaction with human blood plasma, free of excess of plasma (dotted line).

the hemolysis of RBCs was analyzed here for positively and negatively charged porous silica nanoparticles. The hemolysis was evaluated for five concentration of each functionalized nanoparticle ( $\mathrm{Si}-\mathrm{OH}, \mathrm{Si}-\mathrm{NH}_{2}$ and $\left.\mathrm{Si}-\mathrm{P}\left(\mathrm{CH}_{3}\right) \mathrm{O}_{3} \mathrm{H}\right): 32.2,62.5,125,250$ and $500 \mu \mathrm{g} \mathrm{mL}-1$. Positive and negative controls were taken with DI water and PBS. In the first case, when the assays were performed with porous silica nanoparticles dispersions in PBS, up to the maximum concentration used in this study $\left(500 \mu \mathrm{g} \mathrm{mL}^{-1}\right)$, the toxicity was dose-dependent for all samples (see top panel in Figure 4a). Silanol groups on the surface (sample $\mathrm{Si}-\mathrm{OH}$ ) induced the highest toxicity among samples, thus leading to the breaking of more than $50 \%$ of RBCs present in the solution. Sample $\mathrm{Si}-\mathrm{NH}_{2}$ presented the lowest cytotoxic response (10\% of hemolysis). When the hemolytic assay was carried out in a phosphate buffer solution containing human blood plasma, even in low concentrations of plasma such as $2 \%$, it was observed the absence of hemolysis for all samples and all concentrations tested (see bottom panel in Figure 4a). The absence of hemolysis was also observed for hard corona silica nanoparticles obtained after their incubation with $55 \%$ of plasma (data not shown).

By assuming the occurrence of a surface-induced (a) Dispersed in water

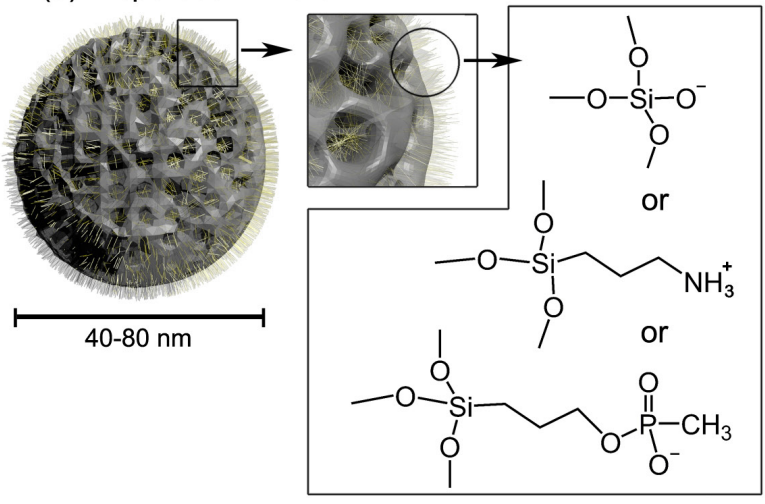

(b) Dispersed in human blood plasma

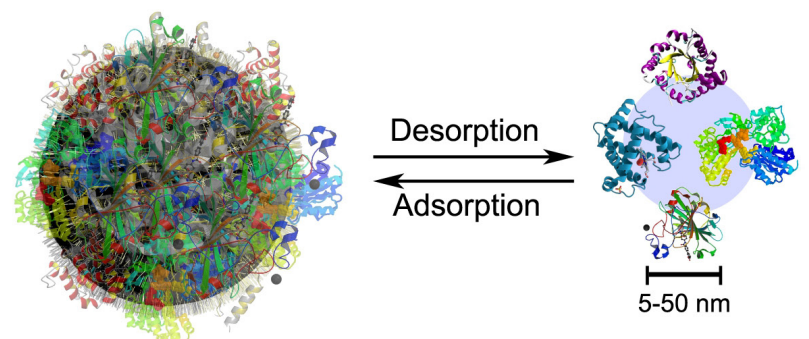

(c) Hemolytic effect of porous silica nanoparticles

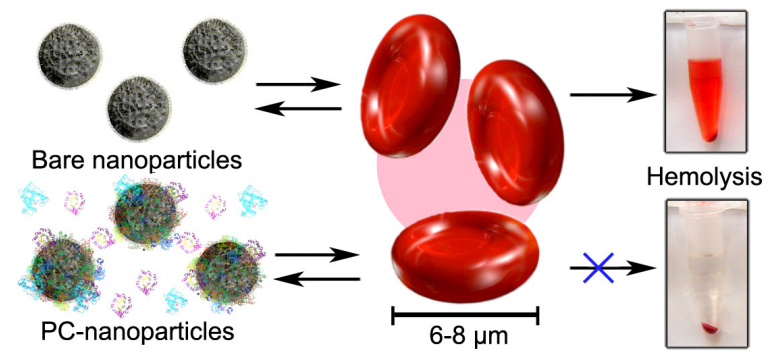

Figure 3. (a) Schematic diagram representing a silica nanoparticle with different external surface chemical groups used in this study: silanol, propylamine and propylmethylphosphonate. (b) Representative scheme showing the dynamic interaction of nanoparticles (regardless the type of surface chemical functionalization) with proteins of human blood plasma (corona effect). (c) Scheme showing the hemolytic effect induced by bare porous silica nanoparticles or by protein-coated nanoparticles (PCnanoparticles). Objects in the diagram are not in scale.

biological effect that leads to the breaking of RBCs, the hemolysis is primarily related to the amount of atoms exposed to cells at the solid-liquid interface, which are responsible for the chemical interactions. Thus, as there is a difference in the specific surface area among samples $\mathrm{Si}-\mathrm{OH}, \mathrm{Si}-\mathrm{NH}_{2}$ and $\mathrm{Si}-\mathrm{P}\left(\mathrm{CH}_{3}\right) \mathrm{O}_{3} \mathrm{H}$, another hemolysis assay in a phosphate buffer solution (without blood plasma) was carried out by normalizing the quantity of nanoparticles used in the experiments by the highest specific surface area $\left(855 \mathrm{~m}^{2} \mathrm{~g}^{-1}\right.$ for sample $\left.\mathrm{Si}-\mathrm{OH}\right)$. Through this experiment, it was observed that the specific surface area-normalized nanoparticles with negatively charged surface (samples $\mathrm{Si}-\mathrm{OH}$ and $\mathrm{Si}-\mathrm{P}\left(\mathrm{CH}_{3}\right) \mathrm{O}_{3} \mathrm{H}$ ) present practically the same citotoxicity. However, even 
(a)
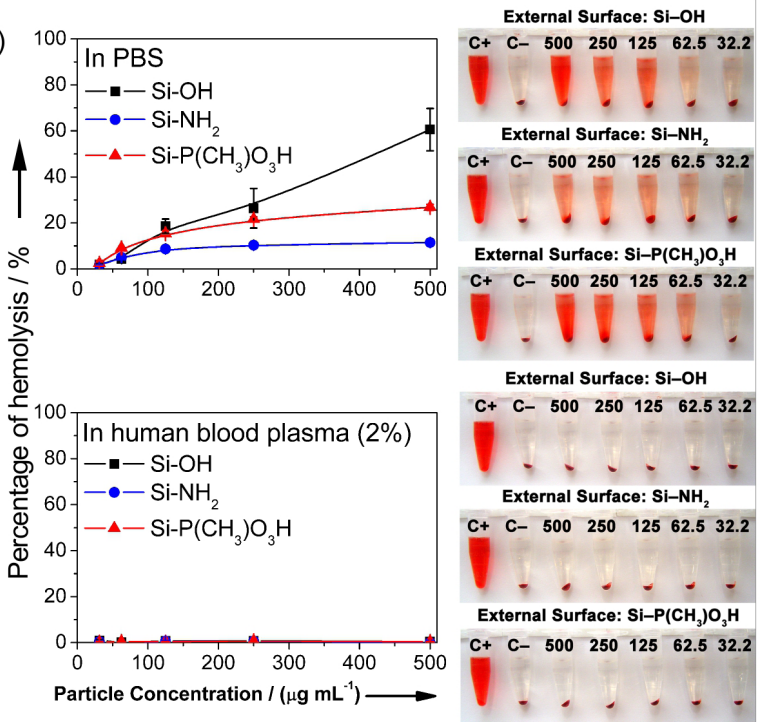

(b)

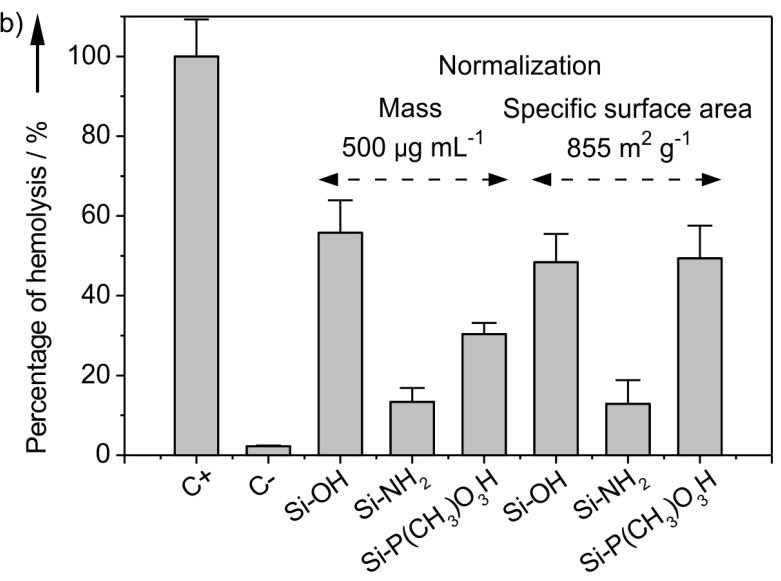

Figure 4. (a) Evaluation of the percentage of hemolysis of RBCs induced by porous silica nanoparticles with three different surface microchemical environment: containing silanols (sample $\mathrm{Si}-\mathrm{OH}$, negatively charged), propylamine (sample $\mathrm{Si}-\mathrm{NH}_{2}$, positively charged) and propylmethylphosphonate (sample $\mathrm{Si}-\mathrm{P}\left(\mathrm{CH}_{3}\right) \mathrm{O}_{3} \mathrm{H}$, negatively charged). The standard deviation is a result of at least three independent tests. Numbers on the right photograph stand for the concentration of particles, and positive and negative controls were done with DI water $(\mathrm{C}+)$ and PBS $(\mathrm{C}-)$, respectively. A photograph of the results is inserted; red color in vials supernatants indicates damaged RBCs (release of hemoglobin). (b) Hemolytic effect of porous silica nanoparticles in PBS (without blood plasma) when samples are normalized in mass or specific surface area.

when its quantity is normalized to achieve $855 \mathrm{~m}^{2} \mathrm{~g}^{-1}$, aminated nanoparticles (sample $\mathrm{Si}-\mathrm{NH}_{2}$ ) still induce a very low cytotoxic effect on RBCs.

In general, the hemolysis of human RBCs induced by silica nanoparticles (without blood plasma) may be associated to reactive oxygen species (ROS) on the surface of the particle, ${ }^{11}$ and electrostatic interactions of deprotonated silanols with proteins membranes ${ }^{28}$ and tetra-alkyl ammonium groups also present in the membranes. ${ }^{13,29}$ As the hemolytic effect of negatively charged silica was practically the same when samples were normalized by specific surface area, it is possible to conclude that not only the negative zeta potential must be considered as the responsible for the citotoxicity of the nanoparticles, once sample $\mathrm{Si}-\mathrm{P}\left(\mathrm{CH}_{3}\right) \mathrm{O}_{3} \mathrm{H}$ possesses a more negatively charged surface. In this way, other mechanisms and interactions such as ROS, hydrogen bonds and van der Waals forces must be considered as responsible for the citotoxicity observed here. On the other hand, the low hemolytic effect induced by sample $\mathrm{Si}-\mathrm{NH}_{2}$ may be mainly associated to the positive value of zeta potential, which cancels the electrostatic interactions with the positively charged tetra-alkyl ammonium groups present in the membranes. However, regardless positive or negative surface charges, the adsorption of plasma biomolecules (mainly proteins) on the nanoparticle surfaces occurred for all samples analyzed. Thus, the suppression of the hemolysis after the protein corona interaction on all samples demonstrates that the biomolecule coating acts as a very efficient surface shielding, thus isolating the surface microchemical environment of the nanoparticle regardless the surface charge (positive or negative), as well as other peculiar chemical characteristics of the surface moieties used (silanol, amine and methylphosphonate).

\section{Conclusions}

This work contributes to add information to the database of physical chemical and toxicological properties of porous silica nanoparticles reported in the literature by using the hemolysis of human red blood cells as a simple short-term in vitro assay towards a safe nanotechnology. It was shown here that human blood plasma suppresses the hemolytic effect of porous silica nanoparticles regardless their surface microchemical environment. Although the phenomenon is clearly observed, there is not yet enough knowledge about the mechanisms that dictates the interactions at the nanoparticle/protein corona/red blood cell interfaces present in the biological milieu. Therefore, understanding the mechanisms of the protein corona interaction and their impact on the cell surface has become an important aspect along with the design of silica-based nanostructures for nanobiotechnology and nanomedicine, and this paper addresses some issues on this direction. Furthermore, the protein corona may be considered not only as an important biological phenomenon that must be recognized hereafter on nanotoxicology, but also a useful coating process that may be used as a tool to minimize nanoparticles toxicity of several materials making them biocompatible for uncountable envisaged applications in nanomedicine. 


\section{Supplementary Information}

Supplementary data and information about characterizations are available free of charge at http://jbcs.sbq.org.br as PDF file.

\section{Acknowledgments}

The authors thank the financial support from FAPESP, CNPq, CAPES (Procad program), INCT-Inomat, INCT-NanoBioSimes and the Brazilian Nanotoxicology Network (CIGeNanotox). D. S. T. M. and A. G. S. F. thank the European Union Seventh Framework Programme (FP7) Small Collaborative project, Neuronano (NMP4-SL-2008-214547).

\section{References}

1. Koo, H.; Huh, M. S.; Sun, I. C.; Yuk, S. H.; Choi, K.; Kim, K.; Kwon, I. C.; Acc. Chem. Res. 2011, 44, 1018.

2. Lee, C. H.; Cheng, S. H.; Wang, Y. J.; Chen, Y. C.; Chen, N. T.; Souris, J.; Chen, C. T.; Mou, C. Y.; Yang, C. S.; Lo, L. W.; Adv. Funct. Mater. 2009, 19, 215.

3. Liong, M.; Lu, J.; Kovochich, M.; Xia, T.; Ruehm, S. G.; Nel, A. E.; Tamanoi, F.; Zink, J. I.; ACS Nano 2008, 2, 889.

4. Lu, J.; Liong, M.; Zink, J. I.; Tamanoi, F.; Small 2007, 3, 1341.

5. Gary-Bobo, M.; Mir, Y.; Rouxel, C.; Brevet, D.; Basile, I.; Maynadier, M.; Vaillant, O.; Mongin, O.; Blanchard-Desce, M.; Morere, A.; Garcia, M.; Durand, J. O.; Raehm, L.; Angew. Chem., Int. Ed. 2011, 50, 11425.

6. Ashley, C. E.; Carnes, E. C.; Phillips, G. K.; Padilla, D.; Durfee, P. N.; Brown, P. A.; Hanna, T. N.; Liu, J. W.; Phillips, B.; Carter, M. B.; Carroll, N. J.; Jiang, X. M.; Dunphy, D. R.; Willman, C. L.; Petsev, D. N.; Evans, D. G.; Parikh, A. N.; Chackerian, B.; Wharton, W.; Peabody, D. S.; Brinker, C. J.; Nat. Mater. 2011, $10,389$.

7. Lee, J. E.; Lee, D. J.; Lee, N.; Kim, B. H.; Choi, S. H.; Hyeon, T.; J. Mater. Chem. 2011, 21, 16869.

8. Tao, Z. M.; Morrow, M. P.; Asefa, T.; Sharma, K. K.; Duncan, C.; Anan, A.; Penefsky, H. S.; Goodisman, J.; Souid, A. K.; Nano Lett. 2008, 8, 1517.

9. Tao, Z. M.; Toms, B. B.; Goodisman, J.; Asefa, T.; Chem. Res. Toxicol. 2009, 22, 1869.

10. Huang, D. M.; Hung, Y.; Ko, B. S.; Hsu, S. C.; Chen, W. H.; Chien, C. L.; Tsai, C. P.; Kuo, C. T.; Kang, J. C.; Yang, C. S.; Mou, C. Y.; Chen, Y. C.; FASEB J. 2005, 19, 2014.
11. Nash, T.; Allison, A. C.; Haringto, J. S.; Nature 1966, $210,259$.

12. Razzaboni, B. L.; Bolsaitis, P.; Environ. Health Perspect. 1990, $87,337$.

13. Slowing, II; Wu, C. W.; Vivero-Escoto, J. L.; Lin, V. S. Y.; Small 2009, 5, 57.

14. Lin, Y. S.; Haynes, C. L.; J. Am. Chem. Soc. 2010, 132, 4834.

15. Yu, T.; Malugin, A.; Ghandehari, H.; ACS Nano 2011, 5, 5717.

16. Urata, C.; Yamada, H.; Wakabayashi, R.; Aoyama, Y.; Hirosawa, S.; Arai, S.; Takeoka, S.; Yamauchi, Y.; Kuroda, K.; J. Am. Chem. Soc. 2011, 133, 8102.

17. Lin, Y. S.; Abadeer, N.; Haynes, C. L.; Chem. Commun. 2011, $47,532$.

18. Trewyn, B. G.; Zhao, Y. N.; Sun, X. X.; Zhang, G. N.; Slowing, I. I.; Lin, V. S. Y.; ACS Nano 2011, 5, 1366.

19. Lundqvist, M.; Stigler, J.; Elia, G.; Lynch, I.; Cedervall, T.; Dawson, K. A.; Proc. Natl. Acad. Sci. U. S. A. 2008, 105, 14265.

20. Cedervall, T.; Lynch, I.; Foy, M.; Berggad, T.; Donnelly, S. C.; Cagney, G.; Linse, S.; Dawson, K. A.; Angew. Chem., Int. Ed. 2007, 46, 5754.

21. Walczyk, D.; Bombelli, F. B.; Monopoli, M. P.; Lynch, I.; Dawson, K. A.; J. Am. Chem. Soc. 2010, 132, 5761.

22. Monopoli, M. P.; Walczyk, D.; Campbell, A.; Elia, G.; Lynch, I.; Bombelli, F. B.; Dawson, K. A.; J. Am. Chem. Soc. 2011, 133, 2525.

23. Paula, A. J.; Montoro, L. A.; Souza Filho, A. G.; Alves, O. L.; Chem. Commun. 2012, 48, 591.

24. Stober, W.; Fink, A.; Bohn, E.; J. Colloid Interface Sci. 1968, 26,62 .

25. Cauda, V.; Schlossbauer, A.; Kecht, J.; Zurner, A.; Bein, T.; J. Am. Chem. Soc. 2009, 131, 11361.

26. Lu, S. L.; Duffin, R.; Poland, C.; Daly, P.; Murphy, F.; Drost, E.; MacNee, W.; Stone, V.; Donaldson, K.; Environ. Health Perspect. 2009, 117, 241.

27. Lynch, I.; Salvati, A.; Dawson, K. A.; Nat. Nanotechnol. 2009, 4, 546.

28. Diociaiuti, M.; Bordi, F.; Gataleta, L.; Baldo, G.; Crateri, P.; Paoletti, L.; Environ. Res. 1999, 80, 197.

29. Depasse, J.; Warlus, J.; J. Colloid Interface Sci. 1976, 56, 618.

Submitted: August 10, 2012

Published online: October 2, 2012

FAPESP has sponsored the publication of this article. 